\title{
Do I Care Enough? Using a Prosocial Tendencies Measure to Understand Twitter Users Sharing Behavior for Minor Public Safety Incidents
}

\author{
Mashael Yousef Almoqbel \\ New Jersey Institute of Technology \\ Ma735@njit.edu
}

\author{
Xun Wang \\ New Jersey Institute of Technology \\ Xw383@njit.edu
}

\author{
Starr Roxanne Hiltz \\ New Jersey Institute of Technology \\ Roxanne.hiltz@gmail.com
}

\begin{abstract}
Social media has been used to assist victims of crises, especially large-scale disasters. Research describes the importance of the crowd who are the first witnesses to any sort of crime or disaster. Among others, this paper focuses on smaller scale public safety incidents such as suspicious activities, and minor robberies. We investigate whether prosocial tendencies affect Twitter users' decisions to share minor public safety incidents on Twitter. The scale used has six subscales including: public, anonymous, dire, emotional, compliant, and altruism. The data $(N=363)$ was collected through Mechanical Turk using an online anonymous survey. Initial results showed a positive relationship between being prosocial and sharing public safety incidents on Twitter. However, once additional variables related to Twitter use were introduced number of public safety official accounts followed, news exposure on social media, and tweet/retweet frequency), these variables fully mediated the relationship. Limitations and design implications are discussed.
\end{abstract}

\section{Introduction}

Social media prevalence is reshaping the world around us. The platforms are heavily used by users of different age groups to share news posts, funny jokes as well as personal and intimate details about their lives. In 2018, at least $73 \%$ of American adults used a form of social media [29].

Social media has been a great resource in fighting crimes and responding to natural disasters; it has been widely utilized by the public and emergency responders, and received considerable attention from research [24,30,34]. Social media has been used to assist victims and reduce the severity of the aftermath of a public safety incident or natural disaster. For example, researchers have used topic modeling to understand people's perceptions on Twitter, right after a large public safety incident [9]. Researchers also [36] proposed a model using crowdsourcing to help in cases of public safety and to understand public attention during disasters.
The Pew Center reports that $24 \%$ of Americans used Twitter in 2018 [29]. Twitter in particular, received attention from researchers and has been used in public safety and disaster incidents. For example, researchers have used visual analytics of Twitter to help emergency responders in disasters [33], and to learn about terrorists and to help in the fight against them [17].

Though social media have demonstrated benefits in public safety situations, it is important to acknowledge that it is the humans using those platforms who decide whether or not to share relevant, accurate, and timely information when needed. Motivations to share posts, stories, information or news articles on social media are relatively well studied in the literature. Research has studied the question of why people retweet [20]. In a more recent work [8], the researchers developed a theory to understand motivations to voluntarily share content online in regard to different individual stages of motivations.

Many of our motivations related to social media use behavior are affected by psychological aspects of our personalities. For example, anonymity is thought to have an effect on decisions to share public safety incidents [14], although previous research was not able to find a direct influence of anonymity on reporting decisions [2]. Traits like altruism, for example, were found to highly affect people's tendency to share on social media [20]. The latter study also stated that the act of "retweeting" is a prosocial behavior. Thus, in this study we use a Prosocial Tendencies Measure (PTM) [4] to understand six different psychological traits and their effect on people's tendency to share public safety tweets on Twitter. The scale includes subscales labelled altruism, compliant, emotional, public, anonymous, and dire.

Large scale disasters, terrorist bombings, and natural disasters have been well researched and well represented in the literature. However, through a thorough literature review done by the researchers, it was found that minor public safety incidents are lacking in research. Examples of minor public safety 
incidents include pick pocketing, stolen items, suspicious persons, unsafe road conditions such as floods, etc. Thus, in this research, we focus on small scale public safety incidents and try to understand how prosocial tendencies affect social media users in terms of sharing information related to such incidents. This would enhance the understanding of researchers and help bridge the gap found in the literature. Also, understanding users' motivations would help in designing social media to promote more involvement from users in cases of minor public safety incidents.

In the remainder of this paper, a more detailed literature review includes description of the Prosocial Tendencies Measure and hypotheses about its anticipated effects on sharing information about public safety issues on social media. Potential mediating variables are then introduced. Research methodology and analysis of results are followed by a discussion which presents a model for further testing, and includes design implications and limitations of the study.

\section{Literature Review}

\subsection{Social Media and Public Safety}

Social media is a rich source for valuable information regarding public safety incidents. Police departments and official offices seek information from the public through social media.

Twitter in particular has been used to study cases of disasters e.g. [13] because its API allows drawing of a sample of public posts related to a topic and/ or a region. Twitter members and emergency managers use it to get emergency updates [28], to receive information about disasters [18], and to know more about how their community is doing during those difficult times [3]. However, past research has focused on large scale disasters such as wildfires [32], bombings [31], floods [18], and terrorism [23]. We would like to explore how social media is used in cases of minor public safety incidents that do not involve a large number of people. In this paper, we explore the impact of internal motivations on sharing information about those incidents on social media.

\subsection{Motivations for Sharing}

Motivations to share on Twitter have been studied previously [20,38], for example, through looking at 'intrinsic' and 'extrinsic' motivations [25]. Another study looked at data from an eastern (Korea) and a western (U.S.) country to understand motivations for sharing marketing information on Facebook [21]. In terms of public safety, prior research looked at three different motivations for reporting incidents on campus [14]. Thus, the general act of sharing on social media, whether it is in the form of reposting, retweeting, or actually typing the content, has been frequently investigated. Although decisions to share based on level of crime severity ranging from high to low was investigated in prior work [15], to the best of our knowledge, there is no previous research looking into motivations to share information related to minor public safety incidents on social media.

\subsection{Prosocial Tendencies Measure}

Prosocial behavior is defined as any voluntary act performed with the goal of benefitting another person [10]. It may be motivated by empathy, altruism, among others. Prosocial behavior does not refer to the same notion as altruism since the helping action (prosocial behavior) of one person could be beneficial for both the helper and the receiver. Although the term "prosocial behavior" is often associated with developing desirable traits in children, the literature on the topic has grown since the late 1980s to include adult behaviors as well.

Existing measures of prosocial behavior can be classified into one of at least two categories, those that assess global (general) prosocial behavior or those that assess prosocial behavior in a specific situation. In this paper, we apply the Prosocial Tendencies Measure (PTM) which is a widely used general measurement for prosocial tendencies in recent years, and which assesses six types of prosocial behaviors: altruistic, compliant, emotional, dire, public, and anonymous. These six different types of prosocial tendencies partly share some common basis, but also can be opposed to each other. The measure was validated by correlations between the six PTM subscales and other variables for which the relationships were consistent with theory and with prior research [4]. Although all the subscales reflect a specific form of prosocial behavior, the goal of the questionnaire is to measure prosocial behavioral tendencies. That is, the measure was designed to assess the tendency of individuals to engage in specific forms of prosocial behaviors.

The six subscales included in the PTM are theoretically important forms of prosocial behaviors that cut across distinct motives and contexts of prosocial behaviors. The prosocial subscales are described as follows: first, altruism is defined as "a motivation to increase another person's welfare" [1]. Second, compliant prosocial behavior is defined as helping others in response to a verbal or nonverbal request [4],[11], and is expected to occur more frequently than spontaneous helping in the general population. Third, emotional prosocial behavior is conceptualized as helping others under emotionally evocative circumstances [4]. Fourth, public prosocial 
behavior is seen as a helping behavior conducted in front of an audience, motivated at least in part by a desire to gain the approval and respect of others and enhance one's self-esteem [4]. Fifth, anonymous prosocial behavior tendencies are defined as helping behaviors where the person receiving the help does not know who offered help [4]. Finally, dire prosocial behavior is defined as helping behavior occurring in crises or emergency situations, which do not always entail emotionally evocative cues [4].

Previous research found that social media platforms are an efficient medium to increase prosocial actions [12]. Since researchers have considered decisions to share on social media as a "prosocial" act [20], we pose the following hypotheses to explore the relationship between prosocial tendencies and decisions to share minor public safety incidents on social media.

- H1. The Prosocial tendencies measure is positively related to decisions to share information on minor public safety situations:

- H1.1 Showing public tendencies, is positively related to decisions to share.

- H1.2 Showing emotional tendencies, is positively related to decisions to share.

- H1.3 Showing dire tendencies, is positively related to decisions to share.

- H1.4 Showing anonymous tendencies, is negatively related to decisions to share.

- H1.5 Showing altruism tendencies, is positively related to decisions to share.

- H1.6 Showing compliant tendencies, is positively related to decisions to share.

Thus, we use the PTM (six subscales: altruistic, compliant, emotional, dire, public, and anonymous) to study how often people have shared minor public safety incident information in the past on Twitter.

\subsection{Mediating Variables}

In order for us to measure the relationship between prosocial tendencies and likeliness to share minor incidents on Twitter, a person must be a Twitter user, and it is more likely that the relationship will occur if the user engages in behaviors on Twitter that predispose them to such sharing. Thus, we introduce several potential mediating variables that measure relevant aspects of Twitter use, including frequency of reading news on Twitter, number of public safety government officials followed, and frequency of tweeting/retweeting (rather than just passively reading the Tweets of others). Therefore, we hypothesize the following, with detailed hypotheses in the sections to follow:
- $\quad$ H2 General patterns of Twitter use will mediate the relationship between PTM and sharing minor public safety incidents on Twitter.

\subsubsection{News Exposure and Followership}

Following someone on social media entails exposure to whatever they post about. When a social media user decides to share a photo or a piece of information, everyone following them will see that update stream in their feed [7]. This is especially relevant in cases of public safety. Prior research found that updates (posting/sharing) on social media are affected by disasters such as earthquakes [22], and there is a temporal shift on Twitter when there is a public safety incident [36], thereby providing an opportunity for shared tweets to reach larger audiences.

Moreover, social media such as Twitter is an important source of news compared to traditional media [19]. The authors found that a retweeted tweet is very likely to reach around one thousand users, regardless of the original tweet owner's number of followers. The latter quantified finding suggests the vast reach and effect of news posted on social media. News posts usually contain reported information about crimes, disasters and mishaps and exposure to this type of news might have an influence on users' tendency to share them. For example, people are affected by what they are exposed to, especially through the updated feed from the accounts they follow. Researchers found that 'repeated exposure' to messages on social media would increase the chances of sharing those messages [37]. In addition to the effect of news exposure on social media, public safety official accounts on Twitter share information about incidents and sometimes seek public safety information from the public [6]. Therefore, exposure to public safety related posts on social media, whether from following public safety official accounts or from reading crime related news, could have an influence on tendencies to share. We hypothesize:

- H2.1 Following public safety government officials on social media is positively related to sharing minor public safety incidents on Twitter and mediates the relationship between prosocial tendencies and the likelihood to share incidents on social media.

- H2.2 Higher news exposure on Twitter is positively related to sharing minor public safety incidents on Twitter and mediates the relationship between prosocial tendencies and the likelihood to share incidents on social media.

\subsubsection{General Engagement Behaviors in Twitter}


Established social media usage habits have been found to influence users' decisions and behaviors. For example, previous research found that the time students spend on Facebook has an effect on students' engagement [16]. Also, more time spent on social media is associated with higher engagement in the form of sharing (retweeting) others' content and generating new content [26]. Another interesting and relevant work [5] found a positive association between the "strength of Facebook use" and participating in "online civic engagement". Sharing public safety incidents on social media is a form of positive civic engagement, therefore, we predict a positive relationship between level of engagement with Twitter and likelihood to share minor public safety incidents on the same platform.

- H2.3 Higher general engagement with Twitter (through retweeting) will be positively related to sharing minor public safety incidents on Twitter and mediates the relationship between prosocial tendencies and the likelihood to share incidents on social media.

\section{Methodology}

\subsection{Sample}

In this research, we used Mechanical Turk to recruit U.S. participants and Survey Monkey to collect the data. Participants were 18 years and older and current Twitter users. A total of 363 responses were found usable for this study. In MTurk, we used features such as high approval rates for participants' work in order to ensure better results. The overall time of the survey was also monitored. All participants submitted responses within reasonable times. Participants' ages ranged from 18 to 57 , with the majority of participants (45\%) reporting 18-27 years. The dataset included responses from female (44.1\%) and male $(54.8 \%)$ respondents. Around (0.3\%) reported other and $(0.6 \%)$ preferred not to report their gender. For ethnicity, participants reported: American Indian or Alaska Native (0.3\%), Asian (4.1\%), Black or African American (9.9\%), Native Hawaiian or Other Pacific Islander $(0.3 \%)$, White $(79.9 \%)$, Mixed race $(3.9 \%)$, and Other $(1.7 \%)$.

\subsection{Procedure}

Participants in the study read and signed a consent form before attempting to complete the survey. They were offered $\$ 1.00$ compensation for their participation in an online survey that required around six minutes to complete. The study was approved by the IRB from a U.S. research university and the study followed the guidelines from the IRB. The survey questionnaire included general demographic questions such as age, gender, ethnicity, education, and parents' education. Information pertaining to various aspects of Twitter usage frequency, including sharing about public safety incidents, was also requested from participants. Lastly, the survey included questions from the Prosocial Tendencies Measure, which is an established scale available for general use. Data collection was done within one week during December 2018. The resulting data were cleaned and analyzed using SPSS.

\subsection{Measures}

In the data cleaning and preparation stage, the authors ran univariate and multivariate analysis and descriptive statistics to understand the boundaries of the data. We ran kurtosis tests and found three variables with abnormal ranges, meaning they were not normally distributed. The variables are: number of followers on Twitter, number of public safety government officials followed, and number of specialists in public safety. The three variables are expected to not have a normal distribution due to the nature of the questions. In order to adjust for the abnormality, we used fractional rank to bring down the kurtosis to a normal range of between 2 and -2 for all variables.

The study used Linear Regression models to test the direct relationship between the dependent and independent variables and to test for mediation. We introduce one control variable which is Education. Previous research found higher education was positively associated with more engagement in social media [26]. We would like to explore if education has any effect on the specific engagement of sharing minor safety incidents on Twitter.

We used a pre-existing and validated scale to measure prosocial tendencies. Thus, we conducted a partial confirmatory analysis in SPSS using Maximum Likelihood. For the rotation method we used Oblimin with Kaiser Normalization. The result of the factor analysis is five clean factors, instead of six, which is what was initially proposed in the actual scale. A total of six items were excluded from the factors because they did not have clear loadings. Two subscales loaded together, which are emotional and dire. Both subscales are very similar and they both are concerned with being compassionate and helpful during extreme situations, thus, having both subscales combined was deemed appropriate. (Contact authors for factor loadings).

Measures for the mediating variables related to general Twitter use and education are shown in the Results section below. 


\subsection{Results}

The dependent variable "how often have you shared minor public safety incidents in the past"
$(M=2.06, S D=1.21)$, was measured using a five-point Likert type scale, ranging from never to very often.

Table 1. Variables Frequencies

\begin{tabular}{cr|r|r|r|r|} 
& & & \multicolumn{3}{|c}{$\begin{array}{r}\text { How often have you shared minor public } \\
\text { safety incidents }\end{array}$} \\
\hline Category & Total N & Percent & \multicolumn{2}{|c|}{ Total N } & Percent \\
\hline 1 Never & 44 & 12.1 & 67 & 44.3 \\
\hline 2 & 40 & 11.0 & 38 & 25.2 \\
\hline 3 & 96 & 26.4 & 25 & 16.6 \\
\hline 4 & 126 & 34.7 & 12 & 7.9 \\
\hline 5 very often & 57 & 15.7 & 9 & 6.0 \\
\hline Total & 363 & 100.0 & 151 & 100 \\
\hline
\end{tabular}

Table 2. Correlations table

\begin{tabular}{|c|c|c|c|c|c|c|c|c|c|}
\hline & Public & $\begin{array}{l}\text { Emotion } \\
\text { al/Dire }\end{array}$ & $\begin{array}{l}\text { Anony } \\
\text { mous }\end{array}$ & Altruism & Compliant & $\begin{array}{l}\text { How } \\
\text { often do } \\
\text { you } \\
\text { tweet or } \\
\text { retweet } \\
?\end{array}$ & $\begin{array}{l}\text { How } \\
\text { often do } \\
\text { you read } \\
\text { news on } \\
\text { Twitter? }\end{array}$ & Education & $\begin{array}{l}\text { Public } \\
\text { safety } \\
\text { officials } \\
\text { followed }\end{array}$ \\
\hline $\begin{array}{l}\text { Shared } \\
\text { minor } \\
\text { public } \\
\text { safety } \\
\text { situations? }\end{array}$ & .135 & $.293^{* *}$ & $.208^{*}$ & -.036 & $-.222^{* \star}$ & $.417^{* *}$ & $.423^{\star *}$ & $-.200^{\star}$ & $.490^{* *}$ \\
\hline Public & 1 & $.199^{* *}$ & -.080 & $-.531^{* *}$ & .017 & .070 & $.122^{*}$ & -.025 & $.234^{* *}$ \\
\hline $\begin{array}{l}\text { Emotional/ } \\
\text { Dire }\end{array}$ & & 1 & $.411^{\star *}$ & -.025 & $-.781^{\star *}$ & $.147^{* *}$ & $.181^{* *}$ & -.016 & $.233^{* *}$ \\
\hline Anonymous & & & 1 & $.153^{\star *}$ & $-.421^{* *}$ & .081 & .033 & $-.105^{*}$ & .083 \\
\hline Altruism & & & & & $-.182^{\star \star}$ & .023 & -.069 & .045 & $-.117^{*}$ \\
\hline Compliant & & & & & 1 & $-.122^{*}$ & $-.152^{* *}$ & .037 & $.215^{\star *}$ \\
\hline $\begin{array}{l}\text { How often } \\
\text { do you } \\
\text { tweet or } \\
\text { retweet? }\end{array}$ & & & & & & 1 & $.437^{* *}$ & -.075 & $.232^{* *}$ \\
\hline $\begin{array}{l}\text { How often } \\
\text { do you read } \\
\text { news on } \\
\text { Twitter? }\end{array}$ & & & & & & & 1 & -.079 & $.344^{* *}$ \\
\hline Education & & & & & & & & 1 & $-.124^{*}$ \\
\hline
\end{tabular}

Note: $* * *: \mathrm{p}<.001, * *: \mathrm{p}<.01, *: \mathrm{p}<.05$

Most participants who answered the question had shared incidents but reported a relatively low frequency for sharing minor incidents on social media (See Table 1 for frequencies). The prosocial tendencies 
subscales used in the analysis were: Public $(M=2.30$, $S D=1.05), \quad$ Emotional/Dire $\quad(M=3.50, \quad S D=0.86)$, Anonymous $(M=3.48, S D=0.92)$, Altruism $(M=4.05$, $S D=1.07)$, and Compliant $(M=3.65, S D=0.99)$. Number of public safety government officials followed was also measured. Due to its skewness, we used fractional ranking to bring down the kurtosis to normal. The new measure ranged from 0.16 to $1.00(M=0.50, S D=0.28)$. The General Twitter usage variable measured with a 5 point Likert type scale included: "How often tweet/retweet" $(M=3.31, S D=1.22)$; See Table 1 for frequencies.

Another mediating variable used in the study was "How often do you read news on Twitter" ( $M=4.70$, $S D=1.85$ ), which was measured using a 7-point Likert type scale ranging from "never" to "very often"; $57 \%$ answered 5-7 on the scale. Education ranged from 1= (No formal educational credential) to $8=$ (Doctoral or professional degree) $(M=4.06, S D=1.65)$; the modal category was "Some college".

For bivariate analysis, we ran Pearson's $r$ correlations for the study variables, shown in Table 2.

As seen in Table 2, the emotional/dire, anonymous, and compliant subscales had significant correlations with likelihood to share minor safety incidents. Also, Twitter usage frequency, education, reading news on Twitter and public safety officials followed had significant correlations with the dependent variable. In order to further test our hypotheses, we used those variables in Linear Regression models using SPSS. We ran two sets of regression models. The first set of models used the Prosocial Tendencies Measure (PTM) as a single factor. The second set of models looked at specific subscales and their effect, if any, on the dependent variable of likelihood to share incidents on social media.

In the first set of models (Table 3), the first model, using only the PTM variables, explained only $6 \%$ of variance (adjusted R-squared= .05) $\mathrm{F}(1,150)=8.75$, $\mathrm{p}<.001$. The second model included education and explained 9\% of variance (adjusted R-squared $=.08$ ) $F(2,150)=6.98$. The third model introduced number of public safety officials followed and was significant, explaining $27 \%$ of variance (adjusted R-squared $=.25$ ) $F(3,146)=17.28$. The fourth model introduced frequency of reading news on Twitter and was significant, explaining 32\% of variance (adjusted Rsquared $=.31) F(4,146)=16.99$. The fifth model introduced overall frequency of tweeting or retweeting and deleted education (which had no longer been significant once other mediators were considered), and was significant, explaining $37 \%$ of variance (adjusted R-squared $=.35) F(4,146)=20.81$.

Table 3. Regression beta coefficients for combined prosocial tendencies measure.

\begin{tabular}{|c|c|c|c|c|c|}
\hline Variable & $\begin{array}{l}\text { Model } 1 \\
\text { Beta's }\end{array}$ & $\begin{array}{c}\text { Model } 2 \\
\text { Beta's }\end{array}$ & $\begin{array}{c}\text { Model } 3 \\
\text { Beta's }\end{array}$ & $\begin{array}{c}\text { Model } 4 \\
\text { Beta's }\end{array}$ & $\begin{array}{c}\text { Model } 5 \\
\text { Beta's }\end{array}$ \\
\hline Prosocial tendencies measure & $.24^{*}$ & $.23^{*}$ & .12 & .10 & .07 \\
\hline Education & & $-.18^{*}$ & -.11 & -.09 & - \\
\hline Public safety government officials followed & & & $.44^{\star * \star}$ & $.34^{* * *}$ & $.34^{* * *}$ \\
\hline How often do you read news on Twitter? & & & & $.27^{*}$ & $.17^{*}$ \\
\hline How often do you tweet or retweet? & & & & & $.26^{*}$ \\
\hline R-squared & .06 & .09 & .27 & .32 & .37 \\
\hline Adjusted R-squared & .05 & .08 & .25 & .31 & .35 \\
\hline
\end{tabular}

Thus, according to the models in Table 3, H1 (the Prosocial tendencies measure is positively related to decisions to share) is initially supported, but its influence is fully mediated by several other variables measuring aspects of general Twitter use.

The second set of models (Table 4) looked at separate prosocial sub-scales as possible independent variables, but otherwise followed the sequence described above. The first model explained $10 \%$ of variance (adjusted R-squared $=.09) F(1,150)=14.01$. In this and all subsequent models using the subscales for Prosocial behavior, only the combined subscales for Emotional and Dire were significant. The second model in this series was significant, explaining $14 \%$ of variance (adjusted R-squared $=.11) F(4,150)=5.16$. The third model was significant, explaining $28 \%$ of 
variance (adjusted R-squared $=.26) \quad F(5,146)=11.05$. The fourth model was significant, explaining $34 \%$ of variance (adjusted R-squared=.31) $\quad F(6,146)=12.11$. The fifth model was significant, explaining 39\% of variance (adjusted R-squared=.36) $F(6,146)=14.60$.

According to Table 4, H1.1 is not supported, H1.2 is partially supported, $H 1.3$ is partially supported, $H 1.4$ is not supported, H1.5 is not supported, and H1.6 is not supported. For the mediating variables, H2 (General patterns of Twitter use will mediate the relationship between PTM and sharing minor public safety incidents on Twitter) was supported. H2.1 was supported. H2.2 was supported. H2.3 was supported.

Table 4. Regression beta coefficients, separate prosocial measures

\begin{tabular}{|c|c|c|c|c|c|}
\hline Variable & $\begin{array}{c}\text { Model } 1 \\
\text { Beta's }\end{array}$ & $\begin{array}{c}\text { Model } 2 \\
\text { Beta's }\end{array}$ & $\begin{array}{c}\text { Model } 3 \\
\text { Beta's }\end{array}$ & $\begin{array}{c}\text { Model } 4 \\
\text { Beta's }\end{array}$ & $\begin{array}{c}\text { Model } 5 \\
\text { Beta's }\end{array}$ \\
\hline Emotional/Dire & $.31^{* \star *}$ & $.29^{*}$ & .16 & .15 & .12 \\
\hline Education & & $-.18^{*}$ & -.11 & -.09 & - \\
\hline Anonymous & & .07 & .06 & .07 & .07 \\
\hline Compliant & & .03 & .02 & .03 & .02 \\
\hline Public safety government officials followed & & & $.41^{* * *}$ & $.31^{* * *}$ & $.31^{* * *}$ \\
\hline How often do you read news on Twitter? & & & & $.27^{* * *}$ & $.18^{*}$ \\
\hline How often do you tweet or retweet? & & & & & $.25^{*}$ \\
\hline R-squared & .10 & .14 & .28 & .34 & .39 \\
\hline Adjusted R-squared & .09 & .11 & .26 & .31 & .36 \\
\hline
\end{tabular}

Note: ${ }^{* * *}: \mathrm{p}<.001, * *: \mathrm{p}<.01, *: \mathrm{p}<.05$

\section{Discussion}

Exhibiting prosocial tendencies was initially found to affect likelihood to share minor public safety incidents on social media. Previous research found that decisions to share on social media are 'prosocial' [20], thus, the result confirms previous findings. However, what's new is that even though the issues to be shared are minor, participants were more likely to share if they exhibit prosocial behaviors. Yet, it is not known if the effect of prosocial tendencies is larger when the scale of the incident changes. Future research in this area might provide more insight and understanding for the magnitude of prosocial tendencies effect on decisions to share public safety incidents, based on their scale.

The Emotional and Dire combined sub-scale was the only sub-scale found to influence decisions to share minor incidents. In previous research, emotional and dire subscales were sometimes used together in a single factor due to their similarity. Previous research found that "emotional words, whether positive or negative, are processed faster than neutral words" [35]. This is a positive finding because emotions during decision making are found to increase the performance of the decision making process [27], which may lead to making better decisions. In the case of public safety, whether small or large, the situation of losing a wallet or being startled by a suspicious person, may raise emotional perceptions of others. Thus, public safety incidents galvanize the need to sympathize with the situation and decide to share the incident to find the perpetrator or simply raise awareness.

Other subscales were not found to have an influence on decisions to share on social media, including public, anonymous, altruism, and compliant subscales. The nature of posting on social media could be perceived as a public act, if using a real identifier, or an anonymous act, if using a pseudonym. Therefore, since we did not control for how posting on social media is perceived, we believe that could be the reason we were not able to see a clear effect on decisions to share. Altruism, on the other hand, was expected to have an influence on the dependent variable, however, it didn't. One possible explanation for the result is the nature of the incident scale being minor. Yet, it is hard to say exactly if this had an effect or not, because the questionnaire used was concerned mainly with minor incidents and did not measure responses if the scale of the incident is larger. The last subscale, compliant, was not found to have an effect on the dependent variable. Being compliant presumes a specific rule or law to follow and abide by. In this research, we did not present hypothetical scenarios of regulations requiring 
individuals to participate. Also, since the scale of the incident is minor, compliant individuals might consider the situation as not alarming and judge that they are not expected to share this incident on social media.

Looking back at the two sets of models presented in Tables 3 and 4, we see that we initially included education as a variable in every model to see how it affected the results. Interestingly, at first, we saw a significant effect of education on decisions to share, however, when other variables are introduced we see the effect washes out. Thus, we decided to remove education from model 5 in both sets of models. Below we present the conceptual model which emerged from our findings (Figure 1).

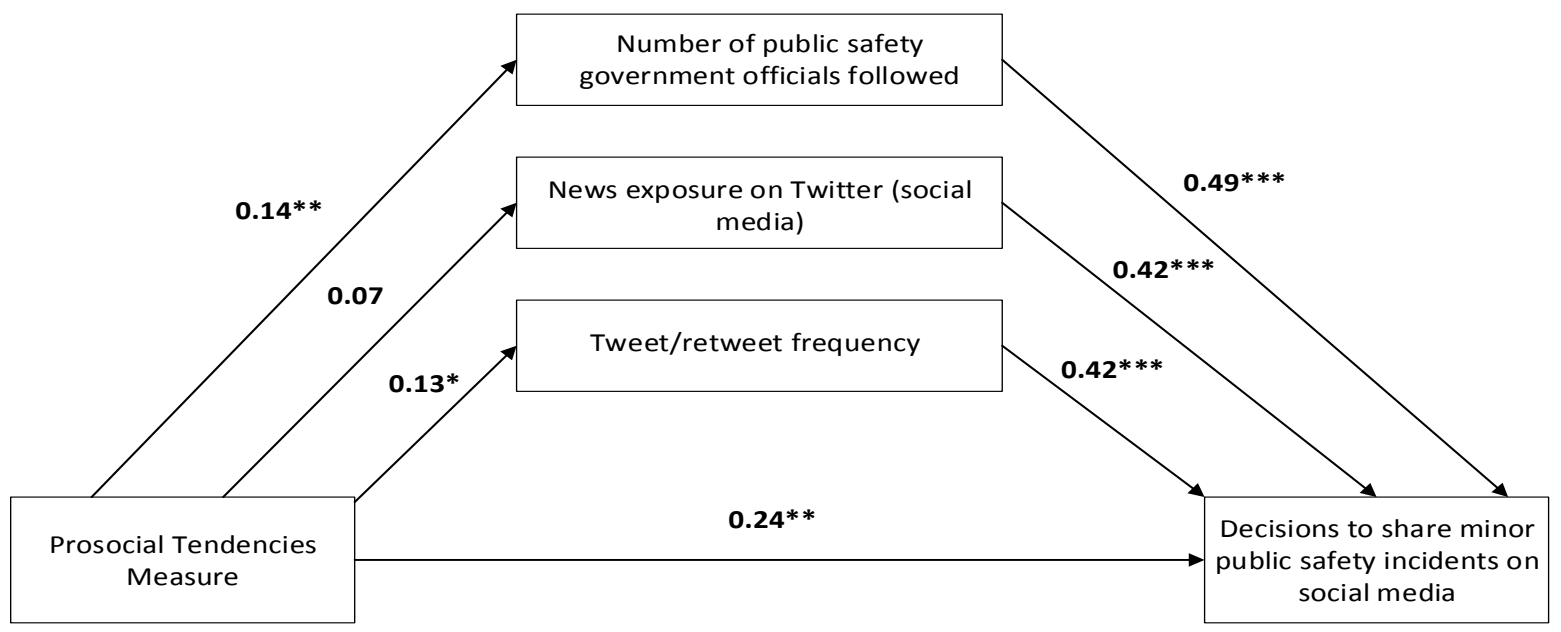

Figure 1: Conceptual model for the mediating variables with beta coefficients.

Note: $* * *: \mathrm{p}<.001, * *: \mathrm{p}<.01, *: \mathrm{p}<.05$

The three variables presented in the middle of Figure 1 were found to act as mediating variables for the relationship between prosocial tendencies and decisions to share. In model 3 (Table 3), when number of public safety government officials followed was introduced to the model, the effect of prosocial tendencies decreased. We deduce from this result that following those accounts on social media is related to Prosocial Tendencies and has a strong positive influence on the followers, which overshadows the effect of internal feelings of prosocial-ness. This is important because it is easier to promote public safety accounts on social media to receive more followership than to actually change the psychological tendencies of social media users.

To further validate the results and the presented conceptual model, in our future research we aim to test it using a larger and more diverse sample and Structural Equation Modeling, which will provide more insight into the complexities of the relationships among the variables.

\subsection{Design Implications}

Generally, although the three mediating variables presented in Figure 1 have a mediating effect on the
Prosocial tendencies relationship with decisions to share, Number of public safety government officials followed was the most prominent variable with the strongest effect on decisions to share. In practice, as stated earlier, those accounts are already seeking the help of the crowd using social media [6]. It would be of great value to increase the popularity of those accounts by advertising them or having social media platforms such as Twitter promote local public safety accounts for their users to encourage them to follow those accounts. When using Twitter, one can see many promoted accounts by the platform which allows for more exposure for the advertised content. The Twitter platform is already involved in business related content promotion. However, future research is recommended with controlling for public safety accounts followings to see if the same results persist.

Another interesting finding is the effect of news exposure on social media on decisions to share public safety incidents. Similar to the previous design suggestion, reliable and local news outlets might be suggested for Twitter users to follow. News on social media, as mentioned earlier, allows for more engagement with the content. Tools such as commenting, liking, and sharing might have an 
influence on the general users' engagement tendency on the platform. However, the direct effect of news on social media use is not clear and therefore, begs for more attention from researchers.

\subsection{Limitations}

There are several limitations of our study which should be mentioned. First, the sampling frame used, Mechanical Turk, consists of people who have volunteered to do "jobs" such as answering surveys for pay, are younger than the general population, and is thus not representative of all adults across the U.S. Because data were collected through a survey with only objective questions and just over 300 participants, it would be desirable to replicate the results involving more participants (a larger sample of Twitter users, and if possible, of users of other platforms too) and some open-ended questions asking people to discuss or describe incidents when they shared information about public safety situations, or decided not to.

\section{Summary and Conclusion}

To summarize, this research looked at motivations for sharing minor public safety incidents, using an adult sample $(\mathrm{N}=363)$ from Mechanical Turk volunteers in the U.S. Using the Prosocial Tendencies Measure and a questionnaire, we found that showing emotional and dire tendencies affects the likelihood of a decision to share minor public safety incidents on social media. Regression models also revealed three mediating factors for prosocial tendencies: number of public safety officials followed, news exposure on social media, and tweet/retweet frequency.

Our main contribution is to add to the understanding of social media users' behaviors in terms of sharing minor safety incidents. We learned that being prosocial is not enough for one to be a volunteer contributor for minor incidents. Perhaps the low-scale severity of the incident affects how people perceive those threats to themselves and to their community. Interestingly, established, independent behaviors on social media such as frequency of sharing and others, showed a clear mediating effect on the relationship between prosocial tendencies and decisions to share minor incidents. This is particularly valuable because it is easier to influence such behaviors through design changes that would change the mediating variables, rather than to try to change complex, psychological traits such as prosocial traits.

\section{Acknowledgements}

(blinded for review)

\section{References}

1. C. Daniel Batson and Adam A. Powell. 2003. Altruism and Prosocial Behavior. In Handbook of Psychology. John Wiley \& Sons, Inc., Hoboken, NJ, USA, 463-484.

2. Leonard Bickman and Helen Helwig. 1979. Bystander reporting of a crime: The Impact of Incentives. Criminology 17, 3: 283-300.

3. D Bird, M Ling, and K Haynes. 2012. Flooding Facebook-the use of social media during the Queensland and Victorian floods. Australian Journal of Emergency Management 27, 1:27-33.

4. G. Carlo and B.A. Randall. 2002. The development of a measure of prosocial behaviors for late adolescents. Journal of Youth and Adolescence 31, 1: 31-44.

5. Ting-Yu Chang. 2016. The Relationship Between Online Social Capital and Civic Engagement - The Case of Facebook Users.

6. Joshua Chanin and Salvador Espinosa. 2016. Examining the Determinants of Police Department Transparency:The View of Police Executives. Criminal Justice Policy Review 27, 5: 498-519.

7. Chien Chin Chen, Shun-Yuan Shih, and Meng Lee. 2016. Who should you follow? Combining learning to rank with social influence for informative friend recommendation. Decision Support Systems 90: 33-45.

8. Kevin Crowston and Isabelle Fagnot. 2018. Stages of motivation for contributing user-generated content: A theory and empirical test. International Journal of Human-Computer Studies 109: 89-101.

9. Qing Deng, Guoray Cai, Hui Zhang, Yi Liu, Lida Huang, and Feng Sun. 2018. Enhancing situation awareness of public safety events by visualizing topic evolution using social media. In Proceedings of the 19th Annual International Conference on Digital Government Research Governance in the Data Age - dgo '18, 1-10.

10. John F. Dovidio, Jane Allyn Piliavin, David A. Schroeder, Louis A. Penner, Jane Allyn Piliavin, David A. Schroeder, and Louis A. Penner. 2017. The Social Psychology of Prosocial Behavior. Psychology Press.

11. Nancy Eisenberg, Tracy L. Spinrad, and Ariel KnafoNoam. 2015. Prosocial Development. In Handbook of Child Psychology and Developmental Science. John Wiley \& Sons, Inc., Hoboken, NJ, USA, 1-47.

12. Jane-Marie Fatkin. 2015. "Pro" social media : using key social psychological theories to increase prosocial engagement on social media sites. Heriot-Watt University.

13. Valentina Grasso and Alfonso Crisci. 2016. Codified hashtags for weather warning on twitter: An Italian case study. PLoS Currents 8, Disasters.

14. Yun Huang, Corey White, Huichuan Xia, and Yang Wang. 2017. A computational cognitive modeling approach to understand and design mobile crowdsourcing for campus safety reporting. International Journal of Human Computer Studies 102, February 2016: 27-40. 
15. Yun Huang, Corey White, Huichuan Xia, and Yang Wang. 2017. A computational cognitive modeling approach to understand and design mobile crowdsourcing for campus safety reporting. International Journal of Human Computer Studies 102: 27-40. https://doi.org/10.1016/j.ijhcs.2016.11.003

16. Reynol Junco. 2012. The relationship between frequency of Facebook use, participation in Facebook activities, and student engagement. Computers \& Education 58, 1: 162 171.

17. Kuljeet Kaur. 2016. Development of a Framework for Analyzing Terrorism Actions via Twitter Lists. International Conference on Computational Techniques in Information and Communication Technologies (ICCTICT).

18. Alisa Kongthon, Choochart Haruechaiyasak, Jaruwat Pailai, and Sarawoot Kongyoung. 2014. The Role of Social Media During a Natural Disaster: A Case Study of the 2011 Thai Flood. International Journal of Innovation and Technology Management 11, 03.

19. Haewoon Kwak, Changhyun Lee, Hosung Park, and Sue Moon. 2010. What is Twitter, a social network or a news media? In Proceedings of the 19th international conference on World wide web - WWW'10, 591.

20. Mina Lee, Hwalbin Kim, and Okhyun Kim. 2015. Why do people retweet a tweet?: altruistic, egoistic, and reciprocity motivations for retweeting. Psychologia 58: 189-201.

21. Mira Lee, Jieun Lee, and Elizabeth Quilliam. 2019. Motivations for sharing marketer-generated content on social media: a comparison between American and Korean college students. Journal of Consumer Marketing 36, 1: 206-217.

22. Rui Li, Kin Hou Lei, Ravi Khadiwala, and Kevin ChenChuan Chang. 2012. TEDAS: A Twitter-based Event Detection and Analysis System. In 2012 IEEE 28th International Conference on Data Engineering, 12731276.

23. Onook Oh, Manish Agrawal, and H. Raghav Rao. 2011. Information control and terrorism: Tracking the Mumbai terrorist attack through twitter. Information Systems Frontiers 13, 1: 33-43.

24. Linda Plotnick and Starr Roxanne Hiltz. 2016. Barriers to Use of Social Media by Emergency Managers. Journal of Homeland Security and Emergency Management 13, 2: 247-277.

25. Henning Rode. 2016. To Share or not to Share: The Effects of Extrinsic and Intrinsic Motivations on Knowledge-sharing in Enterprise Social Media Platforms. Journal of Information Technology 31, 2: 152-165.

26. Carol F. Scott, Laina Y. Bay-Cheng, Mark A. Prince, Thomas H. Nochajski, and R. Lorraine Collins. 2017. Time spent online: Latent profile analyses of emerging adults' social media use. Computers in Human Behavior
75: 311-319.

27. Myeong-Gu Seo and Lisa Feldman Barrett. 2007. Being Emotional During Decision Making — Good or Bad? an Empirical Investigation. Academy of Management Journal 50, 4: 923-940.

28. Jyoti Prakash Singh, Yogesh K. Dwivedi, Nripendra P. Rana, Abhinav Kumar, and Kawaljeet Kaur Kapoor. 2017. Event classification and location prediction from tweets during disasters. Annals of Operations Research: $1-21$.

29. Aaron Smith and Monica Anderson. 2018. Social Media Use 2018: Demographics and Statistics | Pew Research Center. Pew Research Center.

30. Jeannette Sutton, Leysia Palen, and Irina Shklovski. 2008. Backchannels on the front lines: Emergency uses of social media in the 2007 Southern California Wildfires.

31. Jeannette Sutton, Emma Spiro, Sean Fitzhugh, Britta Johnson, Ben Gibson, and Carter Butts. 2014. Terse message amplification in the Boston bombing response. ISCRAM 2014 Conference Proceedings - 11th International Conference on Information Systems for Crisis Response and Management, May: 612-621.

32. Bruno Takahashi, Edson C. Tandoc, and Christine Carmichael. 2015. Communicating on Twitter during a disaster: An analysis of tweets during Typhoon Haiyan in the Philippines. Computers in Human Behavior 50, November 2017: 392-398.

33. Dennis Thom, Robert Kruger, and Thomas Ertl. 2016. Can Twitter Save Lives? A Broad-Scale Study on Visual Social Media Analytics for Public Safety. IEEE Transactions on Visualization and Computer Graphics 22, 7: 1816-1829.

34. Sarah Vieweg, Amanda L. Hughes, Kate Starbird, and Leysia Palen. 2010. Microblogging during two natural hazards events. Proceedings of the 28th international conference on Human factors in computing systems CHI '10: 1079.

35. David Vinson, Marta Ponari, and Gabriella Vigliocco. 2014. How does emotional content affect lexical processing? Cognition and Emotion 28, 4: 737-746.

36. Zheng Xu, Neil Y. Yen, Hui Zhang, Xiao Wei, Zhihan Lv, Kim-Kwang Raymond Choo, Lin Mei, and Xiangfeng Luo. 2017. Social Sensors Based Online Attention Computing of Public Safety Events. IEEE Transactions on Emerging Topics in Computing 5, 3: 403-411.

37. Cangqi Zhou, Qianchuan Zhao, and Wenbo Lu. 2015. Impact of Repeated Exposures on Information Spreading in Social Networks. PLOS ONE 10, 10: e0140556.

38. 2013. Why We Tweet. BizEd 12, 5: 52. 